\title{
A natural experiment on the impact of fruit supplementation on asthma symptoms in children
}

\author{
A.W. Fogarty*, M. Antoniak*, A.J. Venn*, L. Davies* , A. Goodwin", N. Salfield" \\ J.R. Britton* and S.A. Lewis*
}

ABSTRACT: A high fruit intake may reduce the risk of asthma.

The English National School Fruit Scheme was introduced in the East Midlands region of the UK in June 2003 and in the Eastern region in September 2004. Questionnaires were distributed to children aged 4-6 yrs in schools in May 2003. This was repeated in May 2004 when those in the East Midlands had received free fruit for $1 \mathrm{yr}$ and those in the Eastern region had not.

Responses were obtained in 2004 for 4,971 (53\%) and 5,770 (54\%) children in the intervention and control regions, respectively. Despite an increase in fruit consumption in the intervention compared with the control region between 2003 and 2004, there was no difference between the two regions in the prevalence or severity of asthma symptoms after $1 \mathrm{yr}$ of fruit supplementation (odds ratio for wheeze in the past 12 months in intervention compared with control region 1.00, 95\% confidence interval 0.88-1.14).

Providing free fruit at school for $1 \mathrm{yr}$ does not have any immediate effect on prevalence or severity of asthma in young children, although these data do not refute the hypothesis that a higher increase in fruit intake improves measures of asthma control.

KEYWORDS: Asthma, children, diet, fruit

$\mathrm{t}$ has been hypothesised that a reduced consumption of dietary antioxidants may have contributed to the increase in asthma prevalence seen in developed countries over recent decades [1]. Fruit is one of the main dietary sources of antioxidants [2], and a higher intake of fruit has been associated with a lower prevalence of asthma symptoms in many [3-12] but not all published studies of this relationship [13-18]. In children aged 6-7 yrs, those who ate fruit on at least 5 days per week were reported to have $>60 \%$ reduction in the risk of shortness of breath with wheeze compared with those who never ate fruit [5]. However, patterns of antioxidant intake are strongly linked to socio-economic status [2], which may therefore have confounded the observed associations. It is important to clarify the relationship between low fruit intake and asthma, since, if causal, this may permit affordable interventions to both prevent and treat this common childhood disease. Controlled intervention studies are needed to demonstrate the true size of the effect of dietary fruit intake on asthma, but are these are scarce, probably because they are difficult to design and invariably expensive.
The National School Fruit Scheme (NSFS) is a UK government initiative designed to increase fruit intake in children by providing each child aged 4-7 yrs in England with a free piece of fruit each day in school. As this programme was implemented in a phased manner on a region by region basis, the current authors took the opportunity to evaluate the impact of this public health dietary intervention for $1 \mathrm{yr}$ on the prevalence and severity of asthma symptoms in children who received fruit in the scheme in one region of the country, compared with children in another region who did not receive fruit.

\section{METHODS}

\section{Study population}

In May 2003, a random sample of 113 schools in the East Midlands and 122 schools in the Eastern region of England was recruited, and baseline data on diet and respiratory symptoms were collected using a short parentally completed questionnaire from all children who were then in Reception or Year 1 (aged 4-6 yrs) in these schools, as described previously [14]. As part of the phased implementation of the NSFS, children of these ages in the East Midlands region
AFFILIATIONS

*Division of Epidemiology and Public Health, University of Nottingham, and \#Directorate of Public Health East Midlands

Dept of Health, Government Office for the East Midlands, Nottingham, UK.

\section{CORRESPONDENCE}

A.W. Fogarty

Division of Epidemiology and Public Health

Clinical Sciences Building

City Hospital

Nottingham

NG5 1PB

UK

Fax: 441158231946

E-mail: andrew.fogarty@

nottingham.ac.uk

Received:

December 032007

Accepted after revision:

November 182008

\section{SUPPORT STATEMENT}

This study received financial support from the UK Dept of Health.

STATEMENT OF INTEREST

None declared. 
received daily fruit (generally including apples, oranges or pears) in school from June 2003, while those in the Eastern region received similar daily fruit from September 2004 (fig. 1). All of the schools that participated in 2003 were invited to redistribute the same questionnaire in May 2004 to all children in Years 1 or 2 (then aged 5-7 yrs), by which time children in the East Midlands region had received daily fruit for $\sim 1 \mathrm{yr}$, while those living in the Eastern region (which acted as a control group) had not. Ethics approval was obtained from the Eastern Multiple Regional Ethics Committee.

\section{Measurements}

Fruit intake was quantified by asking how many days in a typical week the child ate fruit either at school or at home, excluding fruit juice, and how many pieces of fruit were consumed on average each day. No data were collected on other dietary choices or vitamin supplementation. A continuous measure of the number of pieces of fruit per week was derived by multiplying the number of days on which fruit was eaten per week by the number of pieces of fruit eaten each day. Details of the occurrence of wheeze, exercise-induced wheeze and nocturnal cough were obtained using questions based on standard International Study of Asthma and Allergies in Childhood phrasing [19]. The current authors also asked about asthma diagnosed by a doctor, and whether the child had a bronchodilator or steroid inhaler for asthma and, if so, how many inhaled doses they had used in the past week. The completed questionnaires were scanned and entered into a database (Document Capture Co., Wembley, UK), and responses from 2003 and 2004 were linked. Parents provided their postcode, which was linked using the postcode-enumeration district directory in the Manchester Information and Associated Services to census enumeration district, and in turn to the Townsend Z-score for the 1991 census, as a marker of socio-economic status (a normally distributed measure, with negative scores indicating higher and positive scores lower socio-economic status).

\section{Data analysis and statistical methods}

The prevalence of wheezing in the past 12 months and exercise-induced wheezing and nocturnal cough in the past

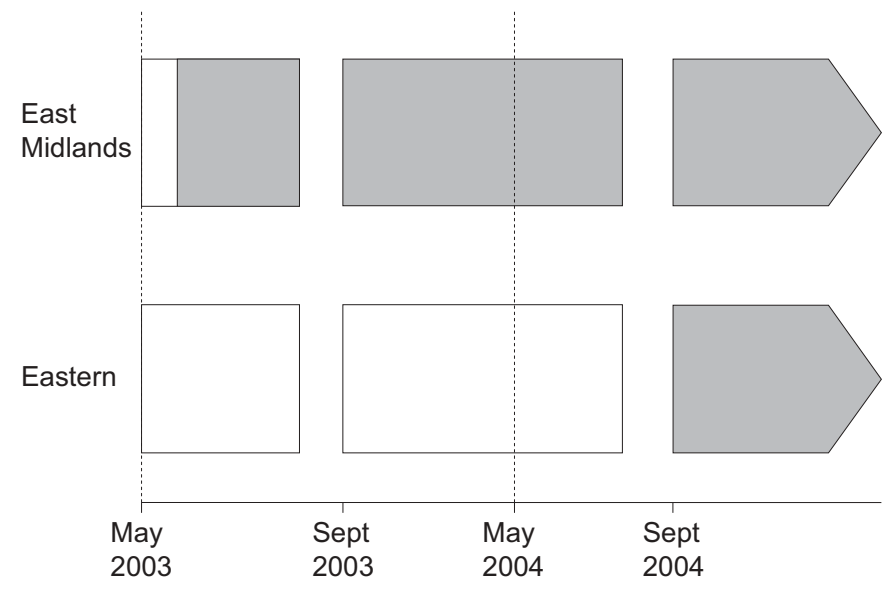

FIGURE 1. A summary of the phased implementation of the National School

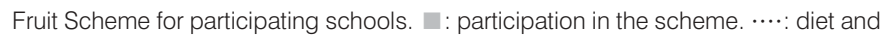
asthma questionnaires given.
12 months were compared, as two alternative indicators of current asthma, between children living in the East Midlands (intervention) and Eastern (control) regions, using the crosssectional data in 2004, and using the paired data for those with responses in 2003 and 2004 to adjust for baseline differences between the two areas. In subgroups of children with asthma in 2003, defined by either current wheezing, use of a bronchodilator or use of a steroid, the occurrence of wheeze in the past 12 months, bronchodilator use and use of a steroid inhaler (markers of persistence of asthma symptoms) were compared between the two regions in 2004. Clustering at school level was allowed for in all analyses. Initially, binary outcomes between intervention and control schools were compared by calculating the individual school proportions and comparing the means or medians of the cluster proportions by independent t-test or Mann-Whitney U-test as appropriate to their distribution. Multi-level modelling in MLWin (Institute of Education, London, UK) and a logistic regression model with a random intercept for school were then used, to determine the odds ratio (OR) and the 95\% confidence interval (CI) for the effect of intervention compared with control on the asthma-related outcomes, and also to adjust for 2003 baseline differences between intervention and control areas. Significance was defined as $\mathrm{p}<0.05$.

Assuming a mean prevalence of wheeze in the past 12 months of $15 \%$ and a standard deviation of $5 \%$ for the distribution of wheeze between schools (data taken from a previous study of primary schools in Nottinghamshire, UK [20]), it was calculated that 100 schools were required in each group to detect a difference of $2 \%$ prevalence of wheeze between the schools that received fruit supplementation at the end of the study and those that did not, with $90 \%$ power and $5 \%$ significance.

\section{RESULTS}

\section{Survey respondents' demographics and fruit consumption}

The recruitment for the study is summarised in figure 2 . The response rates for children from intervention and control schools were $56 \%$ and $52 \%$, respectively, in 2003 , and $53 \%$ and $54 \%$ in 2004. It was possible to link data from 2003 and 2004 for 3,233 and 3,506 children, respectively, representing $58 \%$ of all those who responded in 2003. At baseline in 2003, children in intervention and control schools were comparable in distribution of sex and age (table 1). Fruit intake for all respondents at baseline in 2003 was significantly lower in the intervention compared with the control schools; the estimated median numbers of pieces of fruit per child per week were 8.0 and 10.7, for intervention and control schools respectively. For those who responded in both the 2003 and 2004 surveys, the median baseline fruit intakes were 9.0 and 11.0 pieces of fruit per child per week, for intervention and control schools respectively. In 2004, after the NSFS had been implemented in the intervention region for $\sim 1 \mathrm{yr}$, the weekly median number of pieces of fruit eaten by each child in the intervention region was 14.0, while the comparable quantity for the control region was 12.0 pieces per child per week. The Townsend Index was also higher at baseline for children in the intervention schools than the control schools, reflecting greater social disadvantage (median values -1.2 and -1.4 , respectively). Those who participated in both the 2003 and 2004 surveys were similar in distribution of 
sex and age to those who responded in 2003 (table 1), but were slightly less likely to wheeze.

\section{Asthma symptoms in intervention and control populations}

In 2003, there was no difference in the baseline prevalence of wheeze in the past 12 months at baseline between children in the intervention and control regions (table 1). In 2004, after the children in the intervention region had received fruit at school for $\sim 1 \mathrm{yr}$, there was still no difference in the 12-month period prevalence of wheezing between intervention and control schools; the mean proportions across schools in the intervention and control regions were 11.9 and $12.0 \%$, respectively (OR $1.00,95 \%$ CI $0.88-1.14)$. There was also no difference in 2004 in the prevalence of exercise-induced wheeze (mean proportions 7.9 and $7.5 \%$, respectively; OR $1.05,95 \%$ CI $0.88-1.26)$ or nocturnal cough (20.6 and $18.8 \%$, respectively; OR $1.09,95 \% \mathrm{CI}$ 0.96-1.24). Adjusting for age, sex, Townsend Score, exposure to smoking at home or baseline wheeze prevalence did not alter these results. A post hoc cross-sectional analysis of the 2003 and 2004 data sets demonstrated no association between fruit intake in categories and risk of parentally reported wheeze in the past 12 months in either cross-sectional data set (Chisquared tests for trend: $p=0.22$ and $p=0.40$, respectively).

\section{Asthma symptoms in intervention and control populations in those with asthma symptoms in 2003}

In children who reported current wheeze in 2003, there was no difference in the proportion continuing to wheeze in 2004 (median $67 \%$ for intervention and $67 \%$ for control schools; $\mathrm{p}=0.8$ ) or in the frequency of attacks; the median number of asthma attacks in the past year per child was two, for both the intervention and control schools. In children who had recently

\section{East Midlands (intervention) \\ Eastern (control)}

\begin{tabular}{c|c|c|}
$\begin{array}{c}\text { Consented to } \\
\text { participate in 2003 }\end{array}$ & \multicolumn{2}{|c|}{113 schools } \\
9964 children
\end{tabular}

FIGURE 2. The response rates for schools and individuals for the 2003 and 2004 surveys. used a bronchodilator in 2003, the median proportion of children continuing to use it (at least once in the last week) in 2004 was $67 \%$ for intervention and $50 \%$ for control schools $(p=0.6)$. Most children who were using a steroid in 2003 continued to do so in both intervention and control regions, with a median proportion of $100 \%$ doing so in both regions.

\section{DISCUSSION}

Many cross-sectional studies have reported that a high fruit intake is associated with a lower risk of asthma symptoms [3$12]$, and the need for intervention studies using fruit for asthma symptoms has been highlighted [21]. The present study is the first to look opportunistically at the effect on asthma symptoms of a population-based intervention aiming to increase fruit intake in young children. The findings demonstrate that, despite a $20-25 \%$ increase in weekly fruit intake, fruit supplementation at school had no effect on any of the measures of asthma prevalence or severity in children aged 5-7 yrs.

The present study used a prospective design, comparing prevalence of asthma-related symptoms and change in measures of parentally reported asthma before and after the implementation of the NSFS in one region with those in a second region that acted as a control. The response rate in each region at each time point was reasonable, at $>50 \%$, and was comparable between the two regions. Although only just over half of these children had data for both occasions, these paired data were only used in adjusting for baseline differences, which, for prevalence of respiratory disease, was minimal, and this adjustment had little effect on the results. Participants were informed that they were taking part in a survey of "health and diet" but were not told of the hypothesis being tested, and were unaware of their "control" or "intervention" status, thus avoiding the potential reporting bias observed in conventional intervention studies [22]. Fruit juice intake was not assessed as this was not given as part of the NSFS, is not consistently associated with asthma in the literature and is also particularly difficult to quantify due to confusion with other fruit-flavoured drinks. A median baseline fruit intake of 8-10 pieces per week in the current 2003 study is higher than that reported in national UK surveys of $\sim 6$ pieces per week for children aged 5-7 yrs [23], which may reflect the relatively socially advantaged nature of the current study population as indicated by a median Townsend score of -1.3. This higher baseline fruit intake may be a contributing factor to the negative findings in the present study. The prevalence of asthma of $\sim 13-14 \%$ is consistent with that seen in other comparable surveys [24].

In the context of previous cross-sectional studies suggesting that fruit consumption may be an important exposure influencing asthma symptoms in both children [3-5, 10, 11] and adults $[6-9,21]$, the absence of an effect of increase in fruit intake on measures of asthma symptoms requires consideration. There are several potential explanations for this. First, the duration of the intervention may have been too short, especially as the asthma outcome measures reflected symptoms over the previous 12 months, which encompassed the beginning of the period when fruit supplementation began in the East Midlands. Secondly, the population studied may not have been susceptible to the benefits of fruit supplementation, 


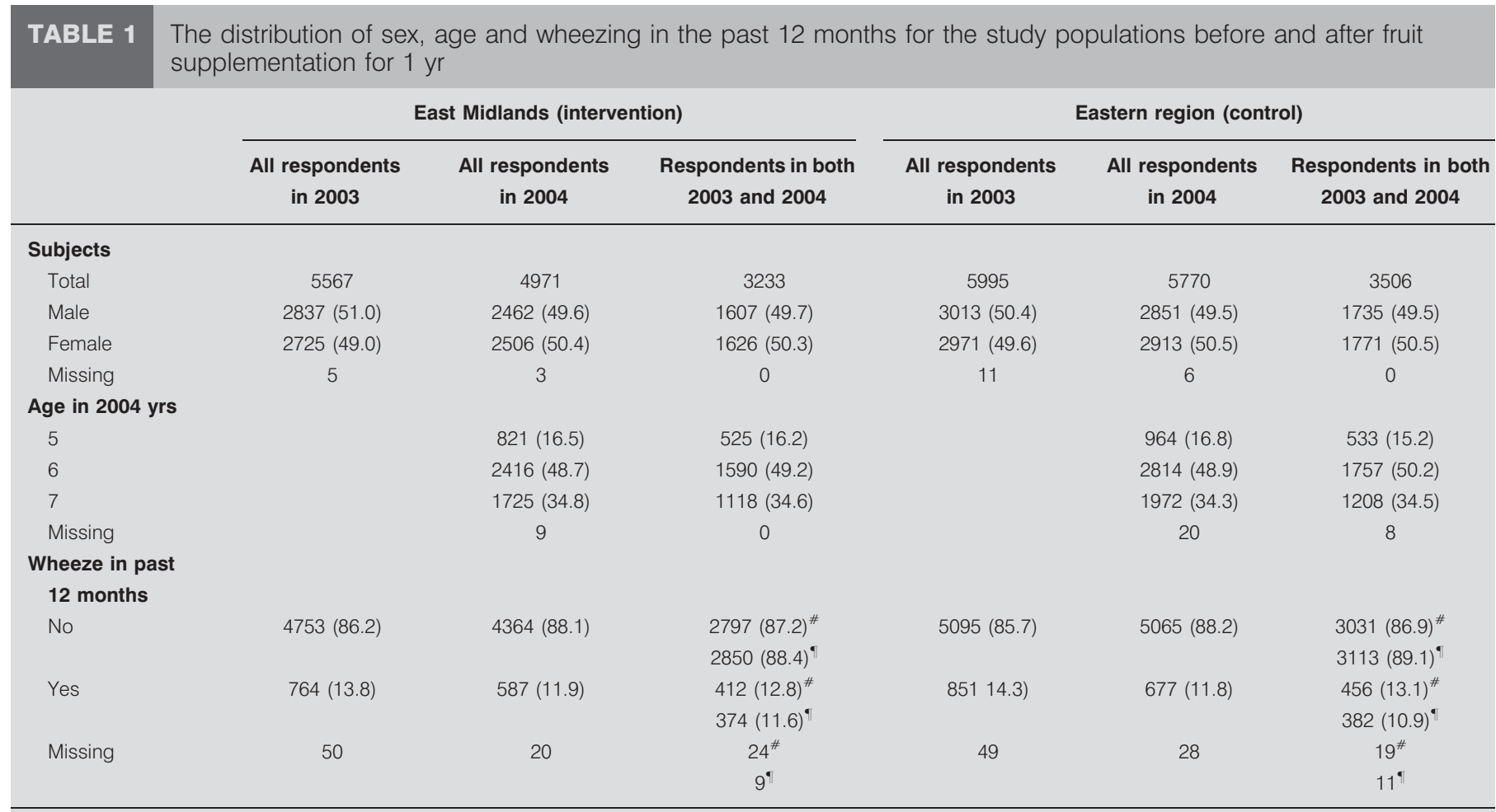

Data are shown at the individual level, and are presented as $n$ or $n(\%) .{ }^{\#}: 2003$ data; ${ }^{\bullet}: 2004$ data.

which may be derived at a younger age when the immune system is less mature. This would be consistent with the data from a retrospective study from Norway, where starting to eat fruit under the age of 1 yr was associated with a $43 \%$ reduction in the diagnosis of asthma in a population with a mean age of 12-13 yrs [25]. Thirdly, the increase in fruit intake may not have been large enough (due to limited consumption of the free daily fruit or one piece of fruit a day not being sufficient) to impact on the pathophysiological processes that drive the development of asthma, and a greater increase in fruit intake may reduce asthma prevalence and severity. The collection of biomarkers would have permitted objective evaluation of fruit consumption, but unfortunately this was incompatible with the opportunistic study design that recruited a relatively large population of children. It is possible that the inability to adjust for factors that are associated with both diet and asthma in children, such as body mass index [26], may have resulted in residual confounding. Finally, the simple possibility has to be considered that there is no causal relationship between fruit intake and asthma and the previously reported observations are a consequence of confounding by other lifestyle factors.

In summary, the provision of daily fruit at school for $1 \mathrm{yr}$ had no impact on the prevalence or severity of asthma symptoms in young children. Despite these observations, the provision of fruit to young children is a public health priority in view of the established health benefits of a diet rich in fruit [27-30].

\section{ACKNOWLEDGEMENTS}

The authors thank the school teaching and secretarial staff who made the survey work possible. Access to data relating to the social deprivation indices was provided by Manchester Information and Associated Services.

\section{REFERENCES}

1 Seaton A, Godden D, Brown K. Increase in asthma: a more toxic environment or a more susceptible population? Thorax 1994; 49: 171-174.

2 Report of the Cardiovascular Review Group Committee on the Medical Aspects of Food Policy. Nutritional aspects of cardiovascular disease. London, Her Majesty's Stationery Office, 2001.

3 Wong GW, Ko FW, Hui DS, et al. Factors associated with difference in prevalence of asthma in children from three cities in China: multicentre epidemiological survey. BMJ 2004; 329: 486-488.

4 Forastiere F, Pistelli R, Sestini P, et al. Consumption of fresh fruit rich in vitamin $C$ and wheezing symptoms in children. SIDRIA Collaborative Group, Italy (Italian Studies on Respiratory Disorders in Children and the Environment). Thorax 2000; 55: 283-288.

5 Farchi S, Forastiere F, Agabiti N, et al. Dietary factors associated with wheezing and allergic rhinitis in children. Eur Respir J 2003; 22: 772-780.

6 Priftanji AV, Qirko E, Burr ML, Layzell JC, Williams KL. Factors associated with asthma in Albania. Allergy 2002; 57: 123-128.

7 Patel BD, Welch AA, Bingham SA, et al. Dietary antioxidants and asthma in adults. Thorax 2006; 61: 388-393.

8 Shaheen SO, Sterne JA, Thompson RL, Songhurst CE, Margetts BM, Burney PH. Dietary antioxidants and asthma 
in adults: population-based case-control study. Am J Respir Crit Care Med 2001; 164: 1823-1828.

9 Butland BK, Strachan DP, Anderson HR. Fresh fruit intake and asthma symptoms in young British adults: confounding or effect modification by smoking? Eur Respir J 1999; 13: 744-750.

10 Antova T, Pattenden S, Nikiforov B, et al. Nutrition and respiratory health in children in six Central and Eastern European countries. Thorax 2003; 58: 231-236.

11 Okoko BJ, Burney PG, Newson RB, Potts JF, Shaheen SO. Childhood asthma and fruit consumption. Eur Respir J 2007; 29: 1161-1168.

12 Diaz-Sanchez D, Tsien A, Casillas A, Dotson AR, Saxon A. Enhanced nasal cytokine production in human beings after in vivo challenge with diesel exhaust particles. J Allergy Clin Immunol 1996; 98: 114-123.

13 Romieu I, Varraso R, Avenel V, Leynaert B, Kauffmann F, Clavel-Chapelon F. Fruit and vegetable intakes and asthma in the E3N study. Thorax 2006; 61: 209-215.

14 Lewis SA, Antoniak M, Venn AJ, et al. Secondhand smoke, dietary fruit intake, road traffic exposures, and the prevalence of asthma: a cross-sectional study in young children. Am J Epidemiol 2005; 161: 406-411.

15 Cook DG, Carey IM, Whincup PH, et al. Effect of fresh fruit consumption on lung function and wheeze in children. Thorax 1997; 52: 628-633.

16 Nagel G, Linseisen J. Dietary intake of fatty acids, antioxidants and selected food groups and asthma in adults. Eur J Clin Nutr 2005; 59: 8-15.

17 Kelly Y, Sacker A, Marmot M. Nutrition and respiratory health in adults: findings from the Health Survey for Scotland. Eur Respir J 2003; 21: 664-671.

18 Tabak C, Wijga AH, de Meer G, Janssen NA, Brunekreef B, Smit HA. Diet and asthma in Dutch school children (ISAAC-2). Thorax 2006; 61: 1048-1053.

19 Worldwide variation in prevalence of symptoms of asthma, allergic rhinoconjunctivitis, and atopic eczema: ISAAC. The International Study of Asthma and Allergies in Childhood (ISAAC) Steering Committee. Lancet 1998; 351: 1225-1232.
20 Venn A, Lewis S, Cooper M, Hill J, Britton J. Increasing prevalence of wheeze and asthma in Nottingham primary schoolchildren 1988-1995. Eur Respir J 1998; 11: 1324-1328.

21 Woods RK, Walters EH, Raven JM, et al. Food and nutrient intakes and asthma risk in young adults. Am J Clin Nutr 2003; 78: 414-421.

22 Harnack L, Himes JH, Anliker J, et al. Intervention-related bias in reporting of food intake by fifth-grade children participating in an obesity prevention study. Am J Epidemiol 2004; 160: 1117-1121.

23 Gregory J. Types and quantities of foods consumed. In: Gregory J, ed. National Diet and Nutrition Survey. 1st Edn. London, Her Majesty's Stationery Office, 2000; p. 59.

24 The International Study of Asthma and Allergies in Childhood (ISAAC) Steering Committee, Worldwide variations in the prevalence of asthma symptoms: the International Study of Asthma and Allergies in Childhood (ISSAC). Eur Respir J 1998; 12: 315-335.

25 Njå F, Nystad W, Lødrup Carlsen KC, Hetlevik O, Carlsen KH. Effects of early intake of fruit or vegetables in relation to later asthma and allergic sensitization in school-age children. Acta Paediatr 2005; 94: 147-154.

26 Weiss ST. Obesity: insight into the origins of asthma. Nat Immunol 2005; 6: 537-539.

27 van't Veer P, Jansen MC, Klerk M, Kok FJ. Fruits and vegetables in the prevention of cancer and cardiovascular disease. Public Health Nutr 2000; 3: 103-107.

28 Bazzano LA, He J, Ogden LG, et al. Fruit and vegetable intake and risk of cardiovascular disease in US adults: the first National Health and Nutrition Examination Survey Epidemiologic Follow-up Study. Am J Clin Nutr 2002; 76: 93-99.

29 Willett WC. Diet and cancer: an evolving picture. JAMA 2005; 293: 233-234.

30 Genkinger JM, Platz EA, Hoffman SC, Comstock GW, Helzlsouer KJ. Fruit, vegetable, and antioxidant intake and all-cause, cancer, and cardiovascular disease mortality in a community-dwelling population in Washington County, Maryland. Am J Epidemiol 2004; 160: 1223-1233. 